\title{
Adequacy of clinical formulae for estimation of energy requirements in children with cystic fibrosis
}

\author{
John J Reilly, T John Evans, Jane Wilkinson, James Y Paton
}

\begin{abstract}
Background-Two clinical formulae (CF conference formula and estimation based on $120 \%$ of average requirement for energy) have been recommended for the estimation of energy requirements in cystic fibrosis but their accuracy is unknown.

Aim-To compare the accuracy of estimates of energy requirement derived from the two formulae.

Methods-Energy requirement, defined as total daily energy expenditure, was measured using the doubly labelled water method in 15 patients (six girls, nine boys; mean (SD) age, 10.0 (2.4) years) who were well and clinically stable. The accuracy of the formulae was assessed using calculation of biases and limits of agreement relative to measured energy requirement. Results-Estimates from the CF conference formula were lower than measured values (mean paired difference, $0.52 \mathrm{MJ} /$ day; $95 \%$ confidence interval $(\mathrm{CI}),-1.10$ to $0.10)$, but this bias was not significant, and was smaller than that from the alternative formula (mean paired difference, 0.77 MJ/day; $95 \% \mathrm{CI},-0.20$ to 1.74$)$. Limits of agreement relative to measured total daily energy expenditure were narrower for the CF conference formula $(-2.72$ to $1.68 \mathrm{MJ} /$ day) than for that based on $120 \%$ of estimated average requirement $(-2.75$ to 4.29 MJ/day), but with both formulae errors in estimation at the individual level were large.

Conclusions-The CF conference formula offers improved prediction of energy requirements, but the accuracy of both formulae at the individual level is not sufficiently good for clinical purposes. (Arch Dis Child 1999;81:120-124)
\end{abstract}

Keywords: cystic fibrosis; energy expenditure; doubly labelled water method

Department of Child Health, University of Glasgow

J Y Paton

Cystic Fibrosis Unit, University of Glasgow T J Evans

J Wilkinson

Correspondence to: Dr Reilly.

email: jir2y@clinmed.gla. ac.uk

Accepted 29 March 1999

Growth retardation and undernutrition remain common complications of cystic fibrosis $(\mathrm{CF}) .{ }^{12}$ Effective prevention and/or management of undernutrition in chronic disease requires provision of energy in appropriate amounts to meet energy needs. Although standard formulae are available for estimation of energy needs in childhood, ${ }^{3}$ these are inappropriate in $\mathrm{CF}$ because the disease is characterised by: abnormal body composition $^{4}$; increased faecal energy losses ${ }^{6}$; increased resting energy expenditure ${ }^{78}$; reduced physical activity ${ }^{9}{ }^{10}$; and a possible increase in total energy expenditure, ${ }^{71}$ although this has been debated. ${ }^{101213}$

In these circumstances, clinical management requires an alternative formula for the estimation of energy requirements. In other chronic diseases of childhood, disease specific formulae have been established, ${ }^{14}{ }^{15}$ and their use has potential clinical advantages. ${ }^{16} \mathrm{~A}$ CF specific formula for clinical estimation of energy requirements has now been available for some years (the CF conference formula), ${ }^{17}$ but it has not been tested formally and is not widely used. In the UK, energy requirements of children with CF are usually estimated using an alternative approach, as $120 \%$ of the estimated average requirement (EAR) for energy. ${ }^{18} 19$ The aim of our study was to compare the accuracy of these two formulae for the estimation of energy requirements in children with $\mathrm{CF}$, by comparison with measurements of total energy expenditure using the doubly labelled water method.

\section{Patients and methods}

PATIENTS AND STUDY POWER

We recruited 15 children. We excluded patients from the study if they were diabetic, if they were non-compliant, or if they were unwell at the time of the study. Therefore, all patients were well, clinically stable, and living as outpatients at the time of our study. The research was approved by the hospital ethics committee and was carried out with the informed consent of children and their families. The study design used paired comparisons of measured and predicted energy requirement, and the sample size was large enough to detect a bias between estimated and measured energy requirement, which was deemed clinically significant (1.0 MJ/day), with standardised difference 1.0 and power 0.90 at the $5 \%$ level.
CLINICAL DATA

We performed standard pulmonary function tests on each child. Genotype and Schwachman score (an index of disease severity) were known for all patients. For descriptive purposes only, growth and nutritional status were assessed by measurement of height to $0.1 \mathrm{~cm}$ using a stadiometer (Holtain Ltd, Crosswell, UK), weight to $0.1 \mathrm{~kg}$ using an electronic scale (Salter, London, UK), and calculation of body mass index (BMI). From this we calculated 
height and BMI standard deviation scores relative to contemporary UK reference data. ${ }^{20}$ The $\mathrm{BMI}$ is a simple but reasonable clinical proxy for body composition, ${ }^{21}$ and so is an index of "protein energy" status. Although there is no gold standard for assessment of paediatric nutritional status, ${ }^{22}$ the BMI, in conjunction with appropriate reference data, is now widely recommended..$^{2023}$

MEASUREMENT OF ENERGY REQUIREMENTS Total daily energy expenditure (TDEE) was measured over 14 days using the doubly labelled water method and equation A6 of Schoeller, ${ }^{25}$ with urine samples obtained from each child predose and then on days 1 and 14 . Each child received a weighed, sterilised dose of $1.6 \mathrm{ml} / \mathrm{kg}{ }^{18} \mathrm{O}$ (10\% enriched) mixed with $0.06 \mathrm{ml} / \mathrm{kg}{ }^{2} \mathrm{H}$ (99.9\% enriched). Food quotients and energy equivalent of $\mathrm{CO}_{2}$ production were determined from three day household measures records: mean (SD) energy equivalent for $\mathrm{CO}_{2}$ production was $23.7(0.3) \mathrm{kJ} /$ litre. Isotopic enrichments of samples and diluted doses were analysed in duplicate by isotope ratio mass spectrometry (Bureau of Stable Isotope Analysis, Brentford, Middlesex, UK). Mean (SD) ratio of dilution spaces $\left({ }^{2} \mathrm{H} /{ }^{18} \mathrm{O}\right)$ was 1.05 (0.02). The energy requirement of a child consists of TDEE plus a small increment to allow for growth (usually $<3 \%$ of TDEE after the 1 st year of life). ${ }^{3}$

Resting energy expenditure (REE) was measured by ventilated hood indirect calorimetry using the Deltatrac system (Datex Corporation, Helsinki, Finland), ${ }^{26}$ after an overnight fast in nine patients. In six patients, a four hour fast was used because of failure to agree on an overnight fast with the child. Once a "steady state" had been reached, each measurement lasted 12-16 minutes. The mean of two to three measurements was used to calculate resting energy expenditure. Those children on $\beta_{2}$ agonist treatment refrained from using it for the period of the fast. The coefficient of variation for this procedure is $<3 \%$ in our laboratory. ${ }^{26}$

We measured faecal fat output by quantitative 72 hour collection during the 14 day study

Table 1 Characteristics of patients

\begin{tabular}{lclllrr}
\hline Patient/Sex & $\begin{array}{c}\text { Age } \\
\text { (years) }\end{array}$ & Genotype & $\begin{array}{l}\text { Shwachman } \\
\text { score }\end{array}$ & $\begin{array}{l}F E V_{1}(\% \\
\text { predicted })\end{array}$ & $\begin{array}{l}\text { BMI } \\
\text { SDS }\end{array}$ & $\begin{array}{c}\text { Height } \\
\text { SDS }\end{array}$ \\
\hline 1/F & 9.1 & 2 & 90 & 83 & -0.15 & -1.40 \\
2/F & 12.3 & 1 & 85 & 67 & 0.18 & 0.70 \\
3/F & 11.0 & 1 & 90 & 93 & -1.32 & 0.76 \\
4/F & 5.1 & 2 & 90 & 105 & 0.79 & 0.85 \\
5/F & 9.3 & 2 & 80 & 78 & -0.98 & -0.56 \\
6/F & 11.4 & 3 & 65 & 54 & 0.42 & 0.44 \\
$7 / \mathrm{M}$ & 9.3 & 1 & 90 & 82 & 0.26 & -0.20 \\
8/M & 7.6 & 2 & 90 & 103 & -0.54 & -1.20 \\
9/M & 7.9 & 1 & 75 & 100 & 0.31 & -1.60 \\
10/M & 15.0 & 1 & 80 & 89 & 0.09 & 0.40 \\
11/M & 10.8 & 1 & 45 & 44 & -1.64 & -1.20 \\
12/M & 8.9 & 1 & 85 & 98 & 0.66 & -0.58 \\
13/M & 12.5 & 2 & 65 & 31 & -1.20 & -1.75 \\
14/M & 8.2 & 1 & 90 & 87 & -0.32 & 0.01 \\
15/M & 11.8 & 2 & 90 & 64 & -1.48 & -0.40 \\
Mean & 10.0 & & 81 & 79 & -0.33 & -0.38 \\
SD & 2.4 & & 13 & 22 & 0.81 & 0.90 \\
\hline G & & & & & & \\
\hline
\end{tabular}

Genotype: 1, homozygous for $\Delta \mathrm{F} 508 ; 2$, heterozygous for $\Delta \mathrm{F} 508$; 3 , other.

$\mathrm{SDS}$, standard deviation score; $\mathrm{FEV}_{1}$, forced expiratory volume in one second. period using the Van de Kamer method. ${ }^{27}$ In each child, dietary fat intake was estimated over three days (one weekend, two weekdays) using a household measures record. The purpose of this was to establish the coefficient of fat absorption (CFA), necessary for the estimation of energy requirements in step 3 of the $\mathrm{CF}$ conference formula.

ESTIMATION OF ENERGY REQUIREMENTS

Energy requirements were estimated for each child by following the steps outlined in the CF conference formula. In brief, they were:

Step 1. Estimation of basal metabolic rate (BMR) using the appropriate World Health Organisation (WHO) prediction equation. ${ }^{28}$

Step 2. Calculation of daily energy expenditure by multiplying BMR by "activity plus disease coefficients". (1) All children were considered as active $(\mathrm{BMR} \times 1.7$ from the formula). (2) Incorporation of disease coefficient based on forced expiratory volume in one second $\left(\mathrm{FEV}_{1}\right)$ as follows: moderate lung disease $\left(\mathrm{FEV}_{1} 40-79 \%\right.$ of predicted), predicted daily energy expenditure $=(\mathrm{BMR} \times(1.7+0.2))$; severe lung disease $\left(\mathrm{FEV}_{1}<40 \%\right.$ of predicted), predicted daily energy expenditure $=(\mathrm{BMR} \times(1.7+0.3)$.

No correction was made for faecal energy losses in 13 of the patients because these were not deemed large enough to merit an adjustment according to the $\mathrm{CF}$ conference criteria (CFA > 0.93). In two patients (numbers 2 and 7), the CFA was lower than the threshold of 0.93 . This necessitated calculation of a third step in the formula for these two children.

Step 3. Estimated TDEE = estimated TDEE (from step 2) $\times(0.93 / \mathrm{CFA})$.

Estimates of energy requirement from the formula were made by one investigator, blind to the calculation of measured energy requirement by another investigator.

\section{STATISTICAL ANALYSIS}

Paired differences between measured and estimated energy requirements were calculated and the significance of these determined by paired $t$ test and 95\% confidence intervals (CI). Agreement between predicted and measured energy requirements at the level of the individual child was tested using an assessment of bias and "limits of agreement". ${ }^{29}$

\section{Results}

Table 1 gives clinical and anthropometric characteristics of the patients. As a group, the children were characterised by relatively mild disease with relatively good growth and nutritional status, but the sample included a wide range of disease severity (table 1).

There was a tendency for mean measured total daily energy expenditure to exceed 
Table 2 Measured and predicted energy expenditure

\begin{tabular}{|c|c|c|c|c|c|}
\hline Patient & $\begin{array}{l}\text { TDEE } \\
\text { (MF/day) } \\
\text { measured }\end{array}$ & $\begin{array}{l}\text { TDEE } \\
\text { (MF/day) } \\
\text { predicted }^{17}\end{array}$ & $\begin{array}{l}T D E E \\
\text { (MF/day) } \\
\text { predicted }(1.2 \times E A R)\end{array}$ & $\begin{array}{l}R E E \\
(M F / \text { day }) * \\
\text { measured }\end{array}$ & $\begin{array}{l}R E E^{\star} \\
\text { (MY/day) } \\
\text { predicted }\end{array}$ \\
\hline 1 & 7.82 & 7.58 & 8.74 & 4.94 & 4.46 \\
\hline 2 & 12.70 & 12.74 & 9.50 & 7.21 & 5.48 \\
\hline 3 & 7.86 & 8.19 & 9.50 & 5.84 & 4.82 \\
\hline 4 & 7.62 & 7.31 & 7.75 & 4.47 & 4.06 \\
\hline 5 & 6.50 & 8.55 & 8.74 & 4.02 & 4.50 \\
\hline 6 & 11.66 & 9.82 & 9.50 & 6.63 & 5.17 \\
\hline 7 & 10.64 & 8.94 & 9.89 & 5.64 & 4.86 \\
\hline 8 & 8.14 & 6.95 & 9.89 & 4.54 & 4.08 \\
\hline 9 & 8.41 & 7.24 & 9.89 & 5.31 & 4.26 \\
\hline 10 & 12.26 & 11.90 & 13.81 & 8.06 & 7.00 \\
\hline 11 & 7.59 & 8.76 & 11.12 & 5.62 & 4.61 \\
\hline 12 & 8.70 & 8.12 & 11.12 & 5.79 & 4.77 \\
\hline 13 & 11.09 & 9.33 & 11.12 & 6.58 & 4.91 \\
\hline 14 & 8.92 & 7.58 & 9.89 & 5.28 & 4.45 \\
\hline 15 & 10.32 & 9.50 & 11.12 & 5.27 & 5.00 \\
\hline Mean & 9.35 & 8.83 & 10.10 & 5.68 & 4.83 \\
\hline SD & 1.93 & 1.66 & 1.42 & 1.98 & 0.72 \\
\hline
\end{tabular}

$\star$ Differences between predicted (WHO formula ${ }^{28}$ ) and measured REE significant (paired $t$ test, $\mathrm{p}$ $<0.05$ ). Other differences between measured and predicted values were not significant. EAR, estimated average requirement; REE, resting energy expenditure; TDEE, total daily energy expenditure. predicted values from the $\mathrm{CF}$ conference formula (table 2), but this difference was small and not significant (by paired $t$ test and 95\% $\mathrm{CI})$. Bias in estimation was $-0.52 \mathrm{MJ} /$ day ( $95 \% \mathrm{CI},-1.10$ to 0.10$)$. This gave a limits of agreement for estimation of -0.52 (2 SD, 2.20) $\mathrm{MJ} /$ day. There was no evidence that the bias in estimation was related to the size of total daily energy expenditure (fig 1 ).

Measured resting energy expenditure consistently exceeded predicted values, (paired $t$ test, $\mathrm{p}<0.05 ; 95 \% \mathrm{CI}, 0.54$ to 1.17 ) (table 2).

Estimates of TDEE using the formula $120 \%$ of EAR tended to exceed measured values (table 2). This difference was not significant (paired $t$ test, $\mathrm{p}>0.05 ; 95 \% \mathrm{CI},-0.20$ to 1.74), but the bias was larger, and limits of agreement between measured and predicted values were wider than for the $\mathrm{CF}$ conference formula at 0.77 (2 SD, 3.52) $\mathrm{MJ} /$ day. There was no evidence that bias in the estimation of TDEE as $120 \%$ EAR was related to the magnitude of TDEE (fig 1).

Figure 1 gives an indication of the errors arising from each method of estimation for individual patients.

\section{Discussion}

Our study showed that both of the clinical formulae for estimating energy requirements of patients with $\mathrm{CF}$ were associated with large errors at the level of the individual patient (fig 1). The evidence that the bias in estimating TDEE was larger, and limits of agreement wider, when using the simple formula $120 \%$ of EAR (fig 1) was not unexpected given the relatively crude nature of this approach and its failure to individualise for activity level, severity of lung disease, and degree of malabsorption. However, this formula is very popular in clinical practice and our results are useful in providing both a quantitative estimate of the errors that arise when it is used, and of its disadvantages relative to the CF conference formula.

Although errors arising from both formulae at the group level were not significant, the limits of agreement that we calculated represent
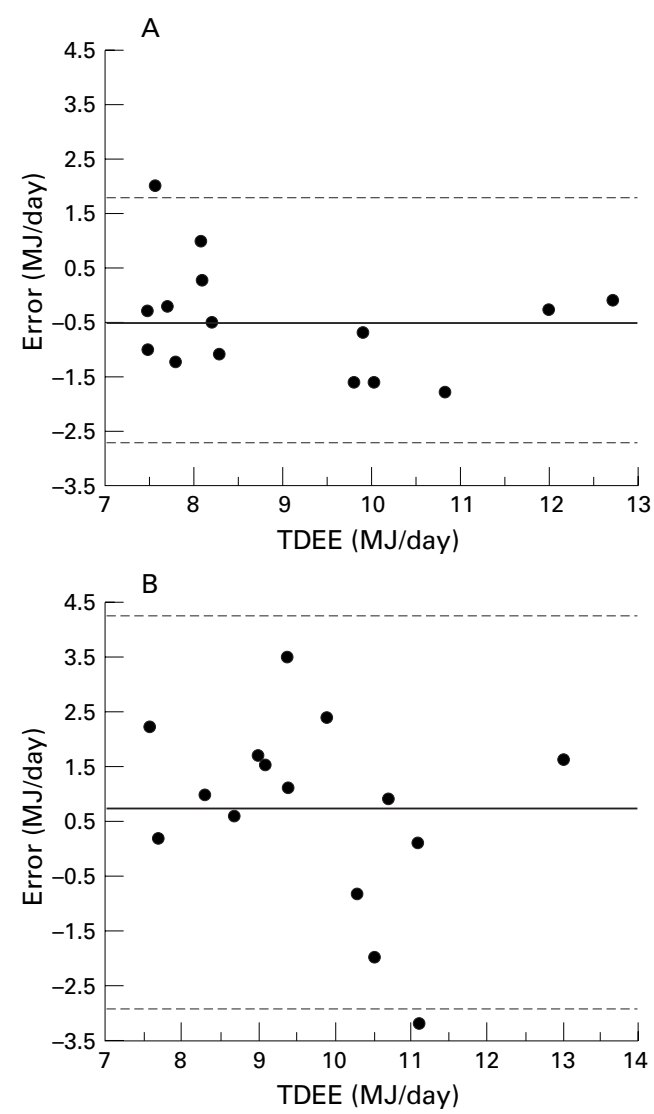

Figure 1 Individual errors (difference between measured and predicted total daily energy expenditure (TDEE): prediction minus measurement) in estimation of TDEE by (A) CF conference formula and (B) using the formula $120 \%$ of estimated average requirement (EAR), in relation to TDEE (mean of measured and predicted values). Horizontal lines represent bias (solid line) and limits of agreement (broken lines).

prediction intervals for individual estimates of energy requirement. The prediction interval for the formula $120 \%$ of EAR ranged from -2.8 to $4.3 \mathrm{MJ} /$ day; that is, from an underestimate of $2.8 \mathrm{MJ} /$ day to an overestimate of $4.3 \mathrm{MJ} /$ day at the individual level. The prediction interval for the CF conference formula was narrower $(-2.7$ to $1.7 \mathrm{MJ} /$ day), although this means that errors in estimation at the individual level were also rather wide. Therefore, we recommend that both formulae are used with caution when estimating energy requirements of individual children. Both formulae are best considered as a "starting point" in estimation, and any judgment of energy needs should be titrated against clinical observations of adequate growth and nutritional status. It is also worth noting that these formulae estimate a minimum energy requirement, and an increment to allow for growth and nutritional repletion should be added when determining the diet prescription.

Accurate estimation of energy requirements of individuals is difficult, even in healthy children, ${ }^{3}$ and might not be achievable using a simple clinical algorithm. Development of better simple algorithms for estimating energy requirements of groups of children is probably more realistic. This might be achievable without further research, because a number of 
studies have now measured TDEE by the doubly labelled water method in children with CF: pooling these data could provide improvements to the existing CF conference formula.

In this case, a number of options could be considered. Predicted BMR from the WHO formula ${ }^{28}$ underestimated REE in our patients with $\mathrm{CF}$, as expected. ${ }^{7810}$ Use of measured REE, where practical, would remove this bias, but might not dramatically improve prediction for individual children. When we incorporated measured REE in place of predicted BMR into the CF conference formula, bias became positive $(0.81 \mathrm{MJ} /$ day $)$, but limits of agreement were still rather wide at -1.35 to $2.90 \mathrm{MJ} /$ day. The absence of a dramatic improvement in accuracy of prediction with the use of measured REE also suggests that much of the error for an individual patient lies in the correction for physical activity. Bias in estimates from the CF conference formula was not related to the size of the TDEE, and so could easily be corrected statistically. However, this would not deal with the problem of errors at the individual level. Physical activity level and/or TDEE can only be established for individuals using techniques such as doubly labelled water, ${ }^{13}$ which are not suitable for most clinical settings, and so the limitations of any approach based on clinical estimation might have to be accepted. In addition, body composition is relevant to energy requirements, ${ }^{318}$ but its measurement would again present serious practical problems in most clinical settings. Lung function might also be relevant. In our study, and in others, ${ }^{4} \%$ predicted $\mathrm{FEV}_{1}$ significantly correlated with nutritional status (BMI SDS: $r=0.52, p<0.05)$ and severity of lung disease might be an important determinant of energy requirement in CF. ${ }^{4}{ }^{17}$ However, the complexity of an algorithm that included measurement of body composition, lung function, and physical activity level would probably preclude clinical use.

Alternative approaches to determination of energy requirements of individual children are available, but have limitations and are not always practical in the clinical setting. One technique that can provide accurate group estimates is to use the measurement of energy intake from gastrostomy fed patients. ${ }^{15}$ If such patients are growing well, their energy intake will represent their energy requirement and so can be used to estimate energy requirement. However, this approach is time consuming, restricted to those children fed by gastrostomy, and does not allow estimation of requirement before the diet prescription is determined. For the child who has CF with reasonable growth and nutritional status, energy requirements are probably being met adequately. For children with poor growth or nutritional status, where a decision is taken to initiate supplementary feeding, or when a group estimate is required for research purposes (to design a nutritional supplementation study for example), a clinical formula might be a useful starting point.

The CF consensus conference ${ }^{17}$ noted that, for the child and adolescent with CF, individualisation of the diet prescription, using appro- priate methods of estimation, is an important element of nutritional management. This remains true given the relatively high prevalence of undernutrition and growth retardation still seen in this patient population, ${ }^{12}$ and the emphasis on diet prescription/nutritional support as a central element of clinical management. ${ }^{2}{ }^{1719} \mathrm{We}$ conclude that the available formulae for children with CF do not permit sufficiently accurate estimates of energy requirement for clinical use with individual patients. Measurement of total energy expenditure would be more accurate, but impractical for most clinical settings.

We acknowledge the support of the Yorkhill NHS Trust CF Research Funds and the Royal Society. We thank the patients and their families for their enthusiasm and willingness to participate, and the CF team for their invaluable support and advice, and the anonymous reviewer for helpful comments on the manuscript.

1 Lai HC, Kosorok MR, Sondel SA, et al. Growth status in children with cystic fibrosis based on national cystic fibrosis patient registry data. F Pediatr 1998;132:478-85.

2 Morrison S, Dodge JA, Cole TJ, et al. Height and weight in cystic fibrosis: a cross sectional study. Arch Dis Child 1997; 77:497-500

3 Torun B, Davies PSW, Livingstone MBE, Paolisso M, Sackett R, Spurr GB. Energy requirements and dietary energy recommendations for children and adolescents $1-18$ years old. Eur 7 Clin Nutr 1996;50:S37-81.

4 Thomson MA, Quirk P, Swanson CE, Shepherd RW. Nutritional growth retardation is associated with defective lung growth in CF. Nutrition 1995;11:350-4.

5 Shepherd RW, Holt TL, Johnson LP, Quirk P, Thomas BJ. Leucine metabolism and body cell mass in cystic fibrosis.

6 Murphy JL, Wootton SA, Bond SA, Jackson AA. Energy Murphy JL, Wootton SA, Bond SA, Jackson AA. Energy
content of stools in normal healthy controls and patients with CF. Arch Dis Child 1991;66:495-500.

7 Tomezsko JL, Stallings VA, Kawchack DA. Energy expenditure and genotype of children with CF. Pediatr Res 1994;35:451-60.

8 Thomson M, Bucolo S, Quirk P, Shepherd RW. Measured versus predicted resting energy expenditure in infants: need for reappraisal. F Pediatr 1995;126:21-7.

9 Levy, LD, Durie PR, Pencharz PB, Corey ML. Effects of long-term nutritional rehabilitation on body composition and clinical status in malnourished children and adolescents with CF. F Pediatr 1985;197:225-30.

10 Spicher V, Roulet M, Schutz Y. Assessment of total energy expenditure in free-living patients with CF. F Pediatr 1991; 118:865-72.

11 Shepherd RW, Holt TL, Vasquez-Velasquez L, Prentice AM. Increased energy expenditure in young children with CF. Lancet 1988;i:1300-3.

12 Bronstein MN, Davies PSW, Hambridge KM. Normal energy expenditure in the infant with presymptomatic CF. 7 Pediatr 1995;126:28-33.

13 Reilly JJ, Edwards CA, Weaver LT. Malnutrition in children with CF: the energy balance equation. $\mathcal{F}$ Pediatr Gastroenterol Nutr 1997;25:127-36.

4 Stallings VA, Zemel BS, Davies JC, Cronk CE, Charney EB. Energy expenditure of children and adolescents with severe disabilities: a cerebral palsy model. Am f Clin Nutr 1996;64:627-34

15 Fried MD, Pencharz PB. Energy and nutrient intakes of children with spastic quadriplegia. F Pediatr 1991;119:9479.

16 Bandini LG, Puelzl-Quinn H, Morelli JA, Fukagawa NK. Estimation of energy requirements in persons with severe central nervous system impairment. F Pediatr 1995;126: 828-32.

17 Ramsey BW, Farrell PM, Pencharz P. Nutritional assessment and management in CF: a consensus report. $A m \mathcal{F}$ Clin Nutr 1992;55:108-16.

18 Department of Health, 1991. Report on health and social subjects, no 41. Dietary reference values for food energy and nutrients for the UK. London: HMSO, 1991.

19 MacDonald A. Nutritional management of CF. Arch Dis Child 1996;74:81-7.

20 Cole TJ, Freeman JV, Preece MA. Body mass index reference curves for the UK, 1990. Arch Dis Child 1995;73: 25-9.

21 Pietrobelli A, Faith MS, Allison DB, Gallagher D, Chiumelo G, Heymsfield SB. Body mass index as a measure of adiposity among children and adolescents: a validation study. F Pediatr 1998;132:204-10

22 Wright JA, Ashenburg CA, Whitaker RC. Comparison of methods to categorise undernutrition in children. $\mathcal{F}$ Pediatr 1995;124:944-6.

23 Rosner B, Porineas R, Loggie J, Daniels BR. Percentiles for BMI in US children. 7 Pediatr 1998;132:211-22.

24 World Health Organisation. Physical status: use and interpretation of anthropometry. Infants and children. 
World Health Organisation Technical Report Series, number 854, 1995:161-262.

25 Schoeller DA, Ravussin E, Schutz Y, Acheson KJ, Baertsch $\mathrm{P}$, Jequier RE. Energy expenditure by doubly-labelled water: validation in humans and proposed calculation. $\mathrm{Am}$ f Physiol 1986;250:R823-30

26 Ventham JC, Reilly JJ. Reproducibility of resting metabolic rate measurement in children. Br F Nutr. [In press.]
27 Van de Kamer JH, ten Bokkel-Huinink H, Weyers HA. Rapid method for determination of fat in faeces. $\mathcal{F}$ Biol Chem 1949;177:347-55.

28 World Health Organisation. Energy and protein requirements. World Health Organ Tech Rep Ser 724 1985;924:178-9. 29 Bland JM, Altman DG. Statistical method for assessing agreement between two methods of clinical measurement. Lancet 1986;i:307-10.

\section{Ketogenic diet again}

When I was a young doctor I was once given the task of approaching a national chain store for a supply of free cream so that a family could afford to start their child on a ketogenic diet. I have followed the ups and downs of the diet's popularity since then with some interest (but I've never had to beg again). It was first used for difficult childhood epilepsy in the USA in the early 1920s. At Johns Hopkins Hospital it has been in use since the 1930s and paediatric neurology staff there retain their enthusiasm for it. They have reported its use in 150 consecutive children (John M Freeman and colleagues. Pediatrics 1998;102:1358-63). Over a period of 24 months in 1994-96 the diet was prescribed for 150 children aged 1-16 who had a mean of 410 seizures a month despite having been treated with an average of more than six antiepileptic drugs. By three months seizure frequency had decreased by $50 \%$ or more in $89(55 \%)$ children and by $90 \%$ or more in $50(33 \%)$. By one year these figures were $50 \%$ and $27 \%$. Younger children were somewhat more likely to respond but seizure type or sex made no significant difference although, as might be expected, many of the children had refractory seizure types of the kind often seen in Lennox-Gastaut syndrome. Fifty five per cent remained on the diet at one year and those who stopped it usually did so because it was not effective.

The Johns Hopkins team consider the ketogenic diet to be more effective for these children than many of the newer drugs, and their families are usually prepared to carry on with it as long as they feel it is effective. Some of the success could possibly be related to the fact that the same dietician has been in charge of the diet at Johns Hopkins for many years.

ARCHIVIST 